GU J Sci, Part C, 7(1): 213-224 (2019)

Gazi Üniversitesi
Fen Bilimleri Dergisi
PART C: TASARIM VE TEKNOLOJI
http://dergipark.gov.tr/gujsc

\title{
Futbol Maçları İçin Bilgisayarlı Görü Destekli Gol Karar Sistemi(GolKaSis): Bir Prototip Çalışma
}

\author{
Emre DANDIL ${ }^{1, *}$, İnanç ÖZKUL ${ }^{1}$

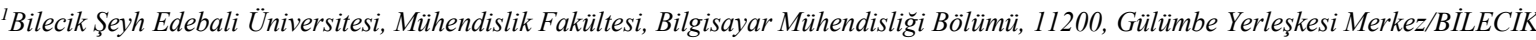

\begin{abstract}
$\ddot{\text { Öz }}$
Makale Bilgisi

Basvuru: 04/12/2018

Düzeltme: 31/01/2019

Kabul: 31/01/2019

\section{Anahtar Kelimeler}

Futbol maçı

Gol çizgisi tespiti

Bilgisayarlı görü sistemi

Haar Kaskad sinıflandırıcı

Futbol maçlarında hakemlerin verebileceği kararlara yardımcı olması amacıyla, otonom sistemlere olan ihtiyaç gün geçtikçe artmaktadır. Bu ihtiyacın ana sebebi hakemlerin önemli maçlarda sonuca etki edebilecek kritik hatalar yapabilmelerinden kaynaklanmaktadır. Bundan dolayı, birçok ülkede futbol maçlarında hakemlerin yanı sıra bilgisayarlı görü sistemine dayalı çalışan yardımcı hakem sistemleri de devreye girmiştir. Bu sistemler ile hakem hataları azaltılarak daha adil bir rekabet ortamı sağlanmaktadır. Bu çalışmada futbol maçlarında gol olayının tespiti için bir bilgisayarlı görü sistemi(GolKaSis) tasarlanmıştır. GolKaSis'te öncelikle, tasarlanan futbol sahası prototipinde uygun bir bölgeye yerleştirilen kameradan alınan videolardan topun kale tam olarak çizgisini geçtiği ve geçmediği pozitif ve negatif görüntüler kullanılarak bir veriseti oluşturulmuştur. Bu görüntülerden pozitif olanlar gol olayını gösterenlerden, negatif olanlar ise gol olayının meydana gelmediği video görüntülerinden oluşmaktadır. Geliştirilen bilgisayarlı görü sisteminde gerçek zamanlı alınan video görüntüleri ile pozitif görüntülerin eşleştirilmesi Haar Kaskad Sınıflandırıcı ile gerçekleştirilerek gol olayı tespit edilmektedir. Tasarlanan prototip üzerinde yapılan test işlemlerinde önerilen bilgisayarlı görü sisteminin gol olayını tespit etmede \%91 başarım gösterdiği görülmüştür.
\end{abstract}

\section{Keywords}

Football match

Goal-line detection

Computer vision system

Haar Cascade classifier

\section{Computer Vision Based Goal Decision System for Football Match: A Prototype Study}

\begin{abstract}
The need for autonomous systems increases day by day in order to be able to appeal to the referee's decisions in soccer. The main reason for this increase in demand is the fact that referees can make critical mistakes that could have an effect on important matches. Therefore, in addition to referees in games, assistant referee systems with a computer vision system have been engaged in soccer games. It is aimed to provide fair competition environment by reducing mistakes with such systems. In this study, a computer vision system, GolKaSis, was designed for the determination of the goal event in football matches. In the GolKaSis, firstly, the images taken from the videos obtained from the cameras placed in a region close to the tower in the designed football field prototype are separated as negative and positive. The ones that are positive from these images are those showing the goal event, the ones that are negative are the video images where the goal event is not coming to fruition. In the developed computer vision system, the matching of the positive video with the video images taken in real time is determined by providing Haar Cascade Classifier. It has been seen that the computerized vision system proposed in the test procedures on the designed prototype correctly determined the goal event with $91 \%$ success rate.
\end{abstract}

\section{GİRIŞ (INTRODUCTION)}

Futbol dünya çapında çok sevilen ve ilgi gören spor dallarının başında gelmektedir. Bu spor dalı günün şartlarına göre yeniliklere de açıktır ve zamanla kurallarında değişiklikler olabilmektedir. Maç sırasında hakemlerin verdiği yanlış kararlardan dolayı bazı takımlar mağduriyet yaşayabilmektedir. 1966 Dünya kupasında İngiltere ve Almanya arasında oynanan müsabakadaki "Wembley Golü" muhtemelen futbol tarihindeki en tartışmalı gol olayıdır. Tartışmalı olmasının nedeni ise pozisyonun gol mü, yoksa gol değil mi olduğunun üzerinde yıllarca farklı fikir üretilmiş olmasıdır[1]. 
Futbol maçlarında bu gibi gol pozisyonları hakkında tartışmaların önüne geçilebilmesi ancak gelişen teknolojinin imkanlarının futbol kuralları ile birleştirilerek, hakemlerin daha doğru ve adil kararlar vermesinin sağlanması ile mümkün olabilir. Bu yardımcı teknolojik yenilikler yüksek çözünürlüğe ve kaliteye sahip kameralar ile alınan görüntülerin gerçek zamanlı işlenerek hakemlerin doğru karar verebilmesini sağlayan bilgisayarlı görü sistemleri olarak adlandırılmaktadır. Son yıllarda, gerçek zamanlı bilgisayarlı görü sistemleri bilgisayar teknolojilerine bağlı olarak inanılmaz bir hızla gelişmiştir. Aynı şekilde makine öğrenmesi sistemleri de hızla gelişmektedir ve birçok alanda uygulamalarını görmek mümkündür[2]. Bilgisayarların giderek boyutlarının küçülmesi, bellek kapasitelerinin ve veri işleme hızlarının artışı ile birlikte karar destek sistemlerinin de başarı oranı artmaktadır. Benzer bir senaryo günümüz futbol karşılaşmaları için de geçerlidir. Futbol maçlarında hakemlerin verebileceği kararlara yardımcı olması amacıyla, otonom sistemlere olan ihtiyaç gün geçtikçe artmaktadır. Bu talep artışının ana sebebi maçlarda hakemlerin önemli maçlarda sonuca etki edebilecek kritik hatalar yapabilmesinden kaynaklanmaktadır.

Spor video verilerinin analiz edilmesi son y1llarda önemli derece artış göstermiştir. Spor olaylarında önemli olan müsabaka anında kararın doğru olarak verilmesi olduğundan, bu amaçla önerilecek sistemlerin gerçek zamanlı, kısa sürede ve otomatik olarak bu işi yapması beklenmektedir. Başta futbol olmak üzere spor dallarının çoğunluğunda tartışmalı pozisyonlar ancak müsabakadan sonra genellikle ağır çekim tekrarını izleme ile net olarak kararlaştırılabilmektedir. Bu alanda önerilecek çalışmaların müsabaka anında kısa sürede işlemi tamamlaması beklenen hedef olmaktadır.

Futbol maçlarında video verilerinden gol olayının tespiti için literatürde araştırmacılar tarafindan farklı yapıda çalışmalar önerilmiştir. Aynı zamanda, gol çizgisi teknolojileri konusunda bilimsel çalışmaların yanında Şahin Gözü, GoalRef gibi ticari uygulamalar da bulunmaktadır. Bu konuda yapılan bilimsel çalışmalar incelendiğinde, çok fazla çalışma olmamakla birlikte, önerilen çalışmaların büyük bir çoğunluğunun video verilerinden topun çizgiyi tam olarak geçip geçmediğinin tespiti konusunda olduğu görülmektedir.

Reid ve Zisserman [3] futbolda gol probleminin çözümü için bilgisayarlı görü temelli bir sistem önermişlerdir. Bu sistemde iki farklı görüş açısından alınan iki görüntü kullanılarak görüntü işleme algoritmaları ile topun çizgiyi geçip geçmediği kontrol edilmektedir. Ancona vd. [4] çalışmalarında tek bir kameradan elde edilen görüntüler yardımıyla futbol maçlarından gol olayının tespitini destek vektör makineleri destekli bir sistem ile tespit etmişledir. Chen vd.[5] çalışmalarında futbol maç videolarından gol olayının otomatik olarak çıkarılması için bir veri madenciliği altyapısı önermişlerdir. Wan vd.[6] ise çalışmalarında, MPEG formatındaki futbol maçı videolarında kale çizgilerini de dikkate alarak, kale-ağzı pozisyonlarının tespiti için Hough Transform tabanlı bir sistem önermişlerdir. Bu çalışmada topun çizgiyi geçip geçmediğin kontrolü konusunda herhangi bir çıkarım yer almamaktadır. D’Orazio vd.[7] çalışmalarında futbol maçlarında gol olayının gerçek zamanlı tespiti için görsel bir sistem önermişlerdir. Sistemde gol çizgisinin her iki tarafında dört farklı kamera yerleştirilerek alınan verileri dört farklı bilgisayar ile eşzamanlı işlenip gol olayının tespiti yapılmaktadır. Eğer top çizgiyi geçerek gol olayı meydana gelmişse hakem bir uyarı sistemi ile bilgilendirilmektedir. Yang vd. [8] çalışmalarında, futbol maçlarının videoları üzerinde gol ağzı pozisyonlarının tespiti ve önemli pozisyonların çıkarılmasına dayalı bir bilgisayarlı görü sistemi önermişlerdir. Bir diğer çalışmada Shi ve Yu [9] videolar üzerinde gol olayının tespiti amacıyla çoklu kurallara dayalı bir çatı önermişledir. Kurallar görsel ipuçları, ses kaynakları ve düzenleme verilerinden oluşmaktadır. Bu alanda yapılan bir diğer çalışmada Khatoonabadi ve Rahmati [10], gol pozisyonlarında hızlı kamera efektleri ile futbolcuların izlenmesi ve sonraki pozisyonların tahmini için bir görü sistemi önermişlerdir. $\mathrm{Bu}$ sistem sayesinde gol sahnelerinin analizi ile menajerlere, futbolculara ve gözlemcilere önemli pozisyonların değerlendirilmesi imkanı sunulmuştur. AO vd. [11] çalışmalarında, futbolda ceza sahasının dışındaki pozisyonların analizi için kameraların kalibrasyonuna dayalı bir bilgisayarlı görü sistemi geliştirmişlerdir. Spagnolo vd. [12] önerdikleri çalışmalarında, bir gol çizgisi görüntüleme sistemi geliştirmişlerdir. Görüntü işleme algoritmalarına göre çalışan sistemde, aday çerçeve içerisinde top belirlenerek gol çizgisini geçip geçmediğinin tespiti yapılmaktadır.

Her ne kadar literatürde farklı yöntemlere dayalı ve teknoloji ile desteklenmiş önerilen gol çizgisi teknolojileri çalışmaları olmasına karşın, bu gibi teknolojilerin futbola girmesinin yararlı olmayacağını savunan çalışmalar da mevcuttur. Örneğin Ryall[13] bir değerlendirme olarak sunduğu çalışmasında, bu gibi teknolojik ve ticari yaklaşımların futbola girmesinin futbolun doğal akışını bozabileceğini, henüz 
yeterince güvenilir sistemler olmadıklarını, bu sistemlerin desteğiyle verilen kararların tartışmaları daha da artırdığını ve test ile kurulum süreçlerinin ise çok fazla maliyet gerektirdiğinden bahsetmiştir.

$\mathrm{Bu}$ çalışmada ise, futbol maçlarında gol olayının tespiti için prototip bir bilgisayarlı görü sistemi(GolKaSis) tasarlanmıştır. Sistemde öncelikle, tasarlanan futbol sahası prototipinde kaleye yakın bir bölgeye yerleştirilen kameradan elde edilen videolardan alınan görüntüler negatif ve pozitif olarak ayrılmıştır. Bu görüntülerden pozitif olanlar gol olayını gösterenlerden, negatif olanlar ise gol olayının meydana gelmediği video görüntülerinden alınarak bir veriseti oluşturulmuştur. Yeterli sayıda görüntü üzerinde işletilen eğitim aşamasından sonra, geliştirilen bilgisayarlı görü sisteminde gerçek zamanlı alınan video görüntüleri ile pozitif görüntülerin eşleştirilmesi ile Haar Kaskad sınıflandırıcı kullanılarak gol olayının tespiti başarılı olarak gerçekleştirilmiştir. Çalışmanın ikinci bölümünde gol çizgisi teknolojileri detaylı olarak sunulmuştur. Üçüncü bölümde çalışmanın materyal ve metot kısmı, dördüncü bölümde GolKaSis'in detaylı açıklaması ve final bölümünde ise çalışmanın sonuçlarına değinilmiştir.

\section{GOL ÇİGGISİ TEKNOLOJILERİ (GOAL-LINE TECHNOLOGIES)}

2012 yılında, gol kararı için uzun süre birçok farklı teknolojinin kullanılmasından sonra, Uluslararası Futbol Birliği Kurulu (IFAB) futbol maçlarında gol çizgisi teknolojisinin(GLT) kullanılmasını resmi olarak onayladı. GLT hakeme topun çizgiyi tam olarak geçip geçmediği konusunda tipik olarak bir görsel izleme aracı sayesinde açık bir gösterim sunmaktadır[14]. Şekil 1'de kale bölgesinde topun gol kararı verilmesinde kullanılan alanlar tanımlanmıştır. Buradan da görülebileceği gibi gol kararının verilebilmesi için topun kale çizgisi olarak belirlenen alanı tamamen çizgiye herhangi bir açıdan değmeyecek şekilde geçmesi gerekmektedir.

Günümüzde GLT sistemleri iki farklı yaklaşım üzerine kurulmaktadır. Bunlardan birincisi video tabanlı yaklaşım iken, ikincisi ise elektromanyetik alan tabanlı yaklaşımdır. Video tabanlı yaklaşımlarda gol bölgesini tam olarak görebilen farklı açılara kameralar yerleştirilerek gol pozisyonları güçlü bir bilgisayar tarafından gerçek zamanlı olarak analiz edilir. Burada üst düzey görüntü işleme algoritmaları ile topun gol çizgisini tam olarak geçip geçmediğinin tespiti yapılır. Elektromanyetik alan tabanlı sistemde, top içerisine yerleştirilen ve genellikle zemine gömülen elektronik devreler kullanılır. Sistemde alıc1/verici devreler yardımıyla topun çizgiyi geçip geçmediği sinyaller aracılığıyla kontrol edilir ve gerektiğinde hakeme bildirim gönderilir[14].

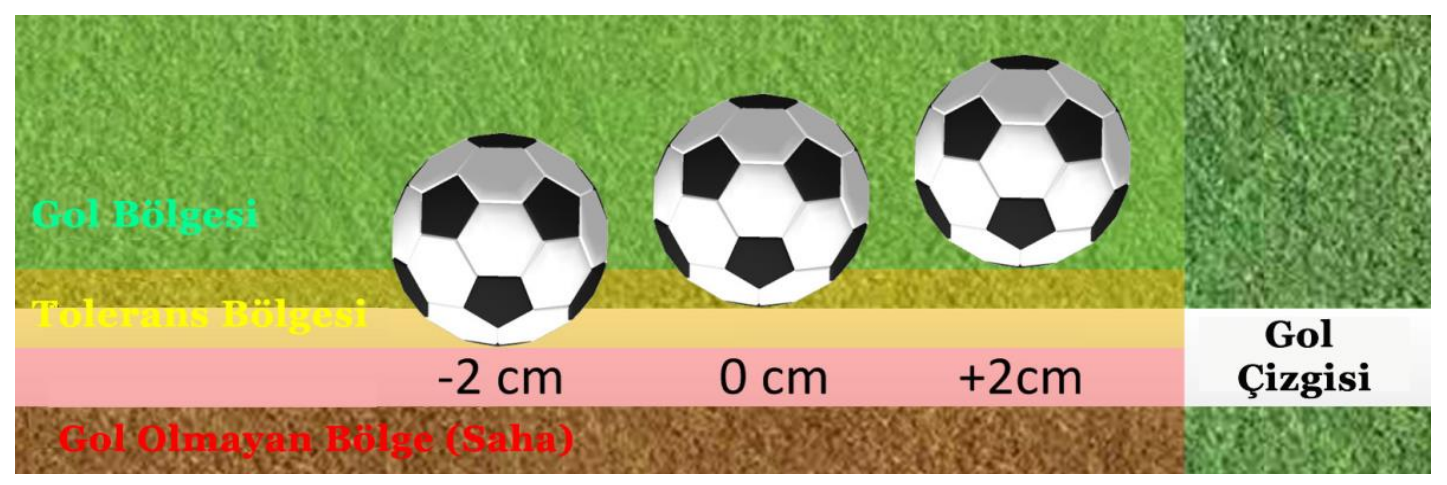

Şekil 1. Gol kararı alanlarının tanımlanması

\section{1 Şahin Gözü (Hawk Eye)}

Şahin Gözü gol çizgisi teknolojisi, stadyum çevresine her iki kale direğini de farklı açılardan görecek şekilde yerleştirilen on dört yüksek çözünürlüklü kameradan alınan videoların görüntü işleme algoritmaları ile güçlü bir bilgisayar tarafından işlenerek gol kararının gerçek zamanlı üç boyutlu olarak verilmesini sağlar[15]. Bu teknoloji uzun bir süredir kriket, tenis ve bilardo için kullanılmaktadır. Bu teknolojide kameralar yüksek hızda topu izler ve pozisyonu hesaplamak için Şekil 2'de görüldüğü gibi üçgen alanları kullanır. Ayrıca bu sistem İngiltere, Almanya ve İspanya gibi liglerin futbol maçlarında da 2014'ten itibaren kullanılmaya başlamıştır. 


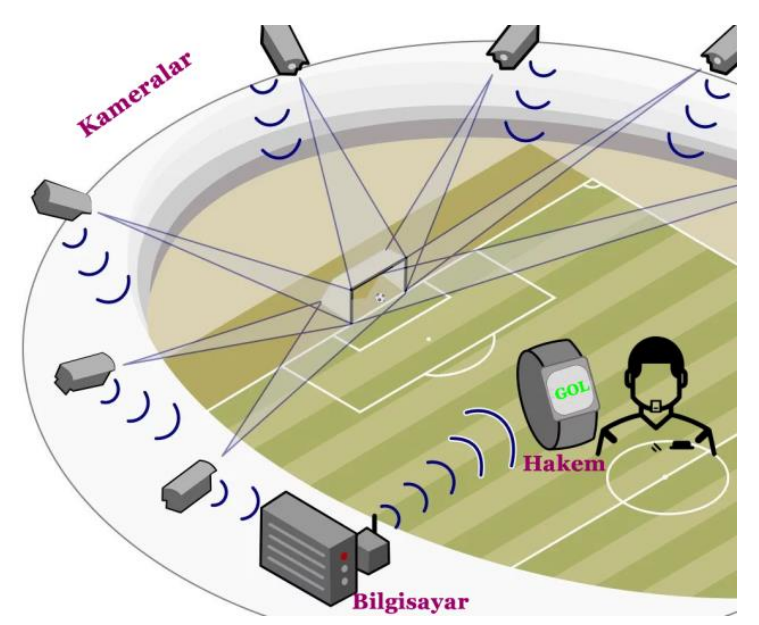

Şekil 2. Şahin Gözü gol çizgisi teknolojisinin stadyuma yerleştirilmesi

\subsection{B Gol Kontrolü (4D Goal Control)}

Bu gol çizgisi teknolojisi Şahin gözüne oldukça benzemektedir. Yine stadyum çevresine yerleştirilen on dört kameradan alınan veriler değerlendirilerek, topun çizgiyi geçip geçmediği belirlenerek pozisyonun gol olup olmadığı tespit edilir[14]. Şahin gözü ile karşılaştırıldığında maliyeti daha yüksek olan bu sistem 2014 Dünya Kupasında kullanılmasına rağmen, daha sonraları kurulum ve sürdürülebilirlik maliyetleri yüzünden pek tercih edilmemiştir.

\subsection{Goalminder}

Video tabanlı başka bir gol çizgisi teknolojisidir. Bu teknolojide kale direklerine yerleştirilen kameralar ile topun çizgiyi geçip geçmediği kontrol edilir[16]. Goalminder sisteminin kale direkleri arasında yerleştirilmiş hali Şekil 3 'te gösterilmiştir.

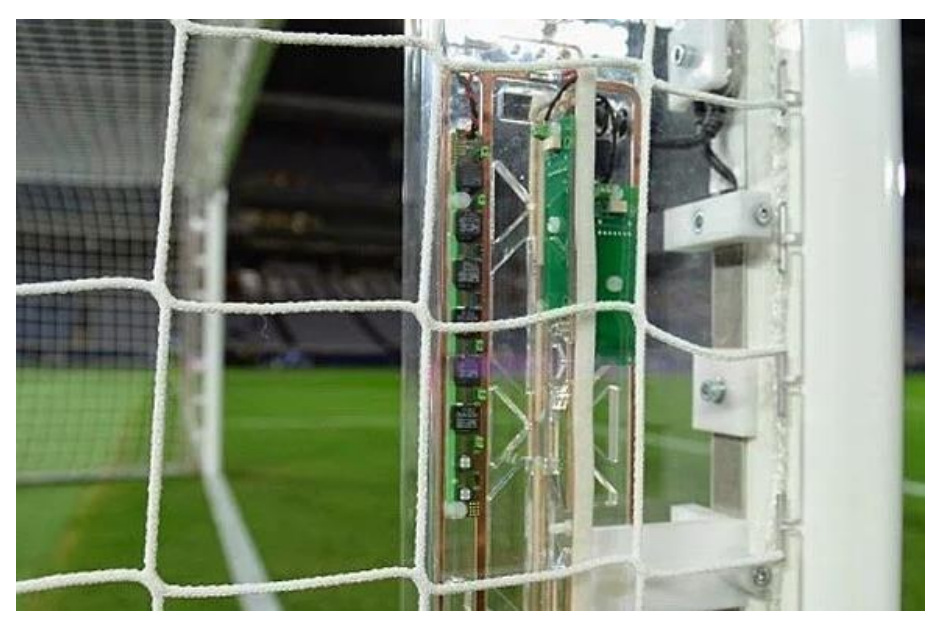

Şekil 3. Goalminder teknolojisi

\subsection{Cairos GLT Sistem (Cairos GLT System)}

Cairos gol çizgisi teknolojisi topu izlemek için elektromanyetik alan kullanır. Topun içerisine yerleştirilen bir elektronik sensör ile topun çizgiyi geçip geçmediği belirlenir[15-16]. Şekil 4'te görülebileceği gibi penaltı noktası ile kale çizgisi arasında oluşturulan manyetik alan ile top izlenir ve bilgiler anten aracılığıla hakeme aktar1lır. 


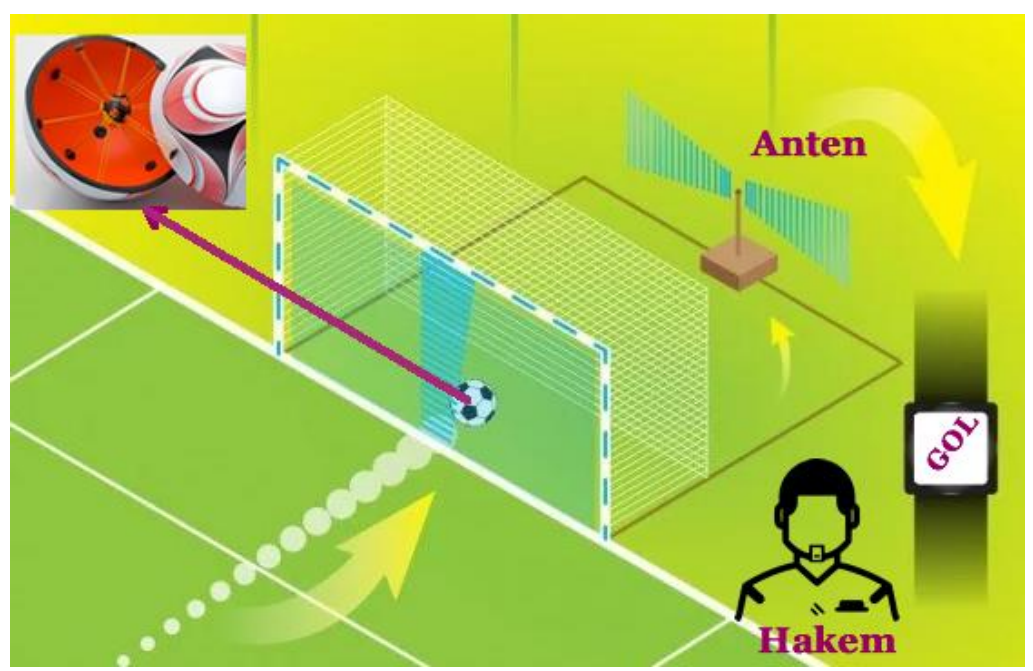

Şekil 4. Cairos GLT sistem

\subsection{GoalRef}

GoalRef gol çizgisi teknolojisi ise topun içerisine yerleştirilen bir elektronik devre ile gol çizgisi bölgesinde oluşturulan manyetik alan geçildiğinde uyarı veren bir sistemden oluşmaktadır. Sistemde bulunan antenler ile kale direkleri arasında manyetik alan oluşturularak, top bu alanı geçer geçmez gol çizgisi uyarı sistem devreye girmektedir[1,15]. 2012 Dünya kupasında sistemin ilk denemesi de yapılmıştır.

\subsection{Video Asistan Hakem(VAR) (Video Assistant Reference)}

Son zamanlarda, sadece gol pozisyonu için değil, maçtaki tüm kritik pozisyonlar için önerilen VAR Sistemi ilk olarak Eylül 2016'da İtalya ile Fransa arasında oynanan hazırlık maçında denenmiştir. Bu sistemde Şekil 5 'te gösterildiği üzere maç esnasında kritik kararlar için hakemlerin karar vermesine yardımcı olmaktadır. Hakem kameralar ile elde edilen verilerden bilgisayarlı görü teknikleri ile kendisine yardımcı araçlar oluşturarak geriye yönelik pozisyonları maçı durdurarak değerlendirdikten sonra nihai kararını vermektedir [17]. Böylece maçı yöneten hakemlerin skoru etkileyebilecek bir pozisyonda kararsız kalmaları halinde, saha kenarına kurulan ekrandan pozisyonu tekrar izleyip karar verebilmektedirler. Ayrıca, kurulan özel bir VAR odasında yer alan ayrı bir hakem heyeti de maçı çok sayıda ekrandan farklı açılardan takip ederek, tartışmalı pozisyonları tekrar izlediklerini maçı yöneten hakeme bildirmektedirler. 2018 Dünya Kupasında FIFA tarafindan maçlarda resmi olarak kullanılmıştır ve birçok futbol liginde uygulanmaktadır.

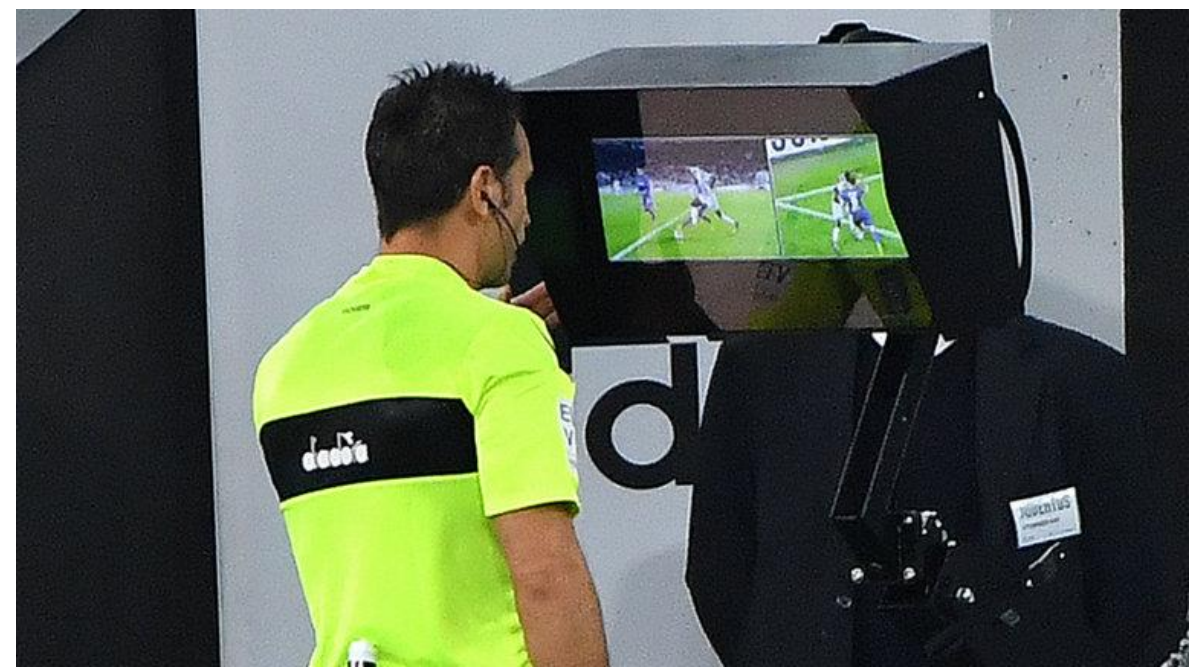

Şekil 5. Futbol maçlarında VAR sisteminin hakemler tarafindan kullanılmast[17] 


\section{MATERYAL VE METOT (MATERIAL AND METHOD)}

Çalışmada kullanılan donanımlar ile teknolojilerin gelen yapısı ve işleyişi Şekil 6'da gösterilmiştir. Kameradan alınan görüntülerin işlenmesi için geliştirilen uygulamalar Python programla dili ile OpenCV Kütüphanesi yardımıyla yürütülmüştür.

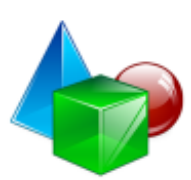

Nesne(Top)

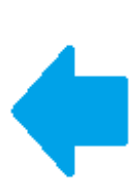

Web Kamerası

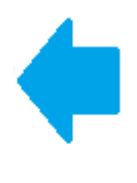

OpenCV
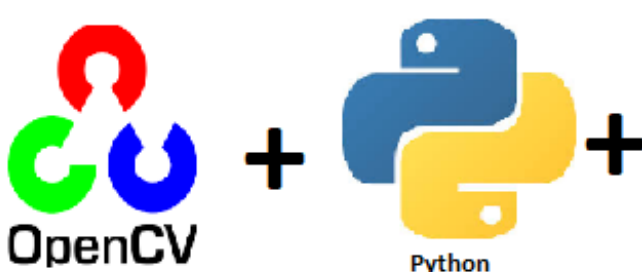

Python

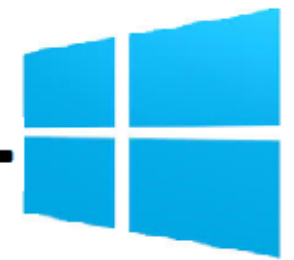

Windows

Şekil 6. Çalışmada kullanılan donanımlar ve teknolojilerin işleyişi

\subsection{OpenCV Kütüphanesi(OpenCV Library)}

OpenCV açık kaynak kodlu bir görüntü işleme kütüphanesidir. C, C++, Python ve Java gibi birçok programlama dil desteği bulunan OpenCV; mobil ve masaüstü olmak üzere farklı platformlarda çalışabilmektedir. OpenCV hesaplama verimliliğini arttırmak amacıyla gerçek zamanlı uygulamalar için tasarlanmıştır [18]. Bu çalışmada tasarlanan bilgisayarlı görü sisteminde topun kale çizgisini geçip geçmediğine göre karar verilecek işlemlerin yapılabilmesi için OpenCV'nin Python için geliştirilmiş Haar kaskad Sınıflandırıcı(Haar Cascade Classifier) kütüphanesinden yararlanımıştır.

\subsection{Haar Kaskad Sınıflandırıcı (Haar Cascade Classifier)}

Görüntü ön-işleme aşamasında akan video çerçevelerinde görüntünün tamamını kullanmak yerine, sadece ilgili nesnenin(top) olduğu kısman odaklanmak, hem işlem hızını artıracak hem de daha yüksek doğruluk oranı elde edilmesini sağlayacaktır. Bu amaç için kullanılabilecek uygun algoritmalardan birisi ViolaJones[19] algoritmasıdır. Çalışmada, Viola-Jones algoritması ile görüntüdeki top kısmı belirlenerek, sadece bu kısma ön-işleme uygulanmıştır. Viola-Jones algoritması videodaki topu belirlemek için dikdörtgen özellikleri kullanarak hem oldukça hızlı çalışmakta hem de yüksek oranda başarım sağlamaktadır. Şekil 7'de Viola-Jones algoritması ile dikdörtgen özelliklerinin çıarılması gösterilmiştir.

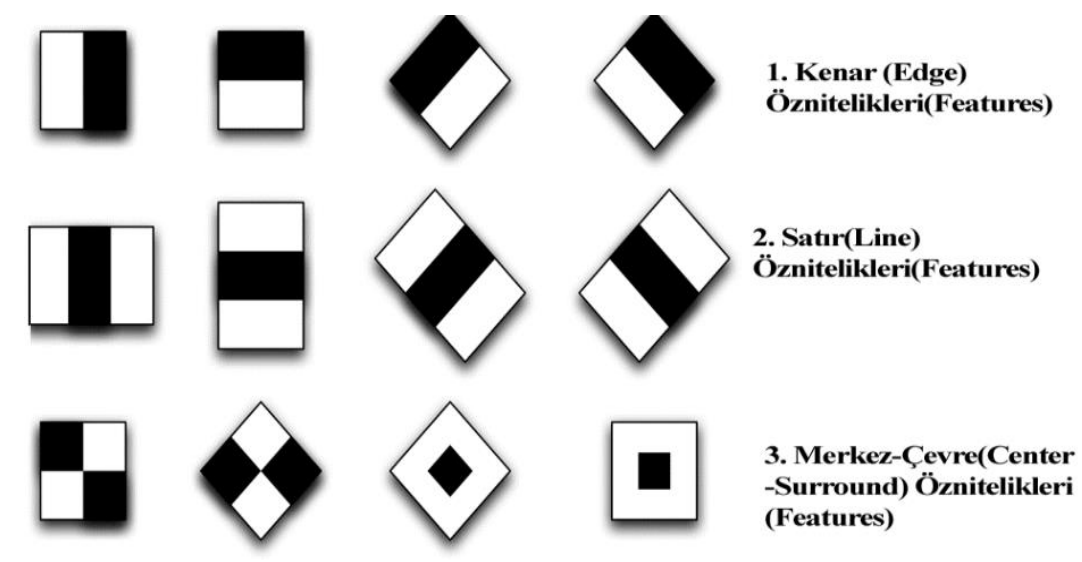

Şekil 7. Viola-Jones dikdörtgen özelliklerinin çıkarılması

Özellik çıkarımından sonra video üzerinde nesne tanıma yapılarak gol olayının belirlenmesi için bir sınıflandırıcı kullanılmalıdır. Haar sınıflandırıcı, özellik tabanlı kaskad sınıflandırıcılarını kullanarak makine öğrenimine dayalı etkili bir nesne algılama yöntemidir[20]. Kaskad işlevi birçok pozitif ve negatif 
görüntüden eğitilerek daha sonra diğer görüntüdeki nesneleri tespit etmek için kullanılır. Haar' da her özellik, Viola-Jones algoritmasındaki siyah dikdörtgenin altındaki piksellerin toplamından beyaz dikdörtgenin altındaki piksellerin toplamının çıkarılmasıyla elde edilen tek bir değerden oluşmaktadır. Böylece her bir çekirdeğin olası tüm boyutları ve konumları birçok özelliği hesaplamak için kullanılmış olmaktadir.

$\mathrm{Bu}$ çalışmada top tespiti işleminde Haar sınıflandırıcıyı eğitmek amacıyla bir eğitim veriseti oluşturulmuştur. Eğitim veriseti, hem içerisinde bulunması istenen nesnenin yer aldığı pozitif resimleri hem de yer almadığ 1 negatif resimleri içermektedir. Pozitif resim içerisindeki nesneyi tespit etmek amacıyla 24x24 piksel boyutlarındaki alt-pencereler tüm resim boyunca kaydırılarak nesne taramas1 gerçekleştirilerek Cascade Trainer GUI[21] yazılımı ile eğitim işlemi gerçekleştirilmektedir. Bu pencereler Haar-benzeri öznitelikler olarak adlandırılmaktadır. Tüm resim içerisinde bu işlemi yaparken zaman kaybını azalmak için AdaBoost algoritması kullanılmaktadır. Negatif önyükleme kullanarak AdaBoost sınıflandırıcı yapısı Viola-Jones algoritması ile birlikte kullanılmaktadır[22].

\subsection{Görüntü Veriseti(Dataset)}

Çalışmada kullanılan veri kümesi tasarlanan gerçek saha prototipi üzerinde çekilen videolardan elde edilen görüntüler kullanılarak oluşturulmuştur. Aynı zamanda oluşturulan veri setinde yanlış etiketlenmiş bazı görüntüler elenerek her bir sınıf için en küçük kenarı 240 piksel olacak şekilde görüntü elde edilmiştir. Bu görüntüler RGB formatında, toplamda 3600 görüntüden oluşan bir veri kümesini meydana getirmiştir. Daha sonra bu veri kümesi, eğitim ve test olarak gruplandırılmıştır. Gol olayını gösteren pozitif küme toplam 2600 görüntüden oluşurken, negatif kümesinde ise 1000adet görüntü bulunmaktadır. Pozitif ve negatif kümelerinde kullanılan 2600 ve 1000 örnek sayıları, akan videodan en uygun çerçevelerin seçilmesi ile elde edilmiştir. Gol olayını gösteren pozitif kümedeki görüntü sayısı en optimum eğitim ağ1 oluşturmak için daha fazla belirlenmiştir. Şekil 8'de veri kümemizdeki kullanılan topun farklı açılardan elde edilmiş görüntüleri görülmektedir.
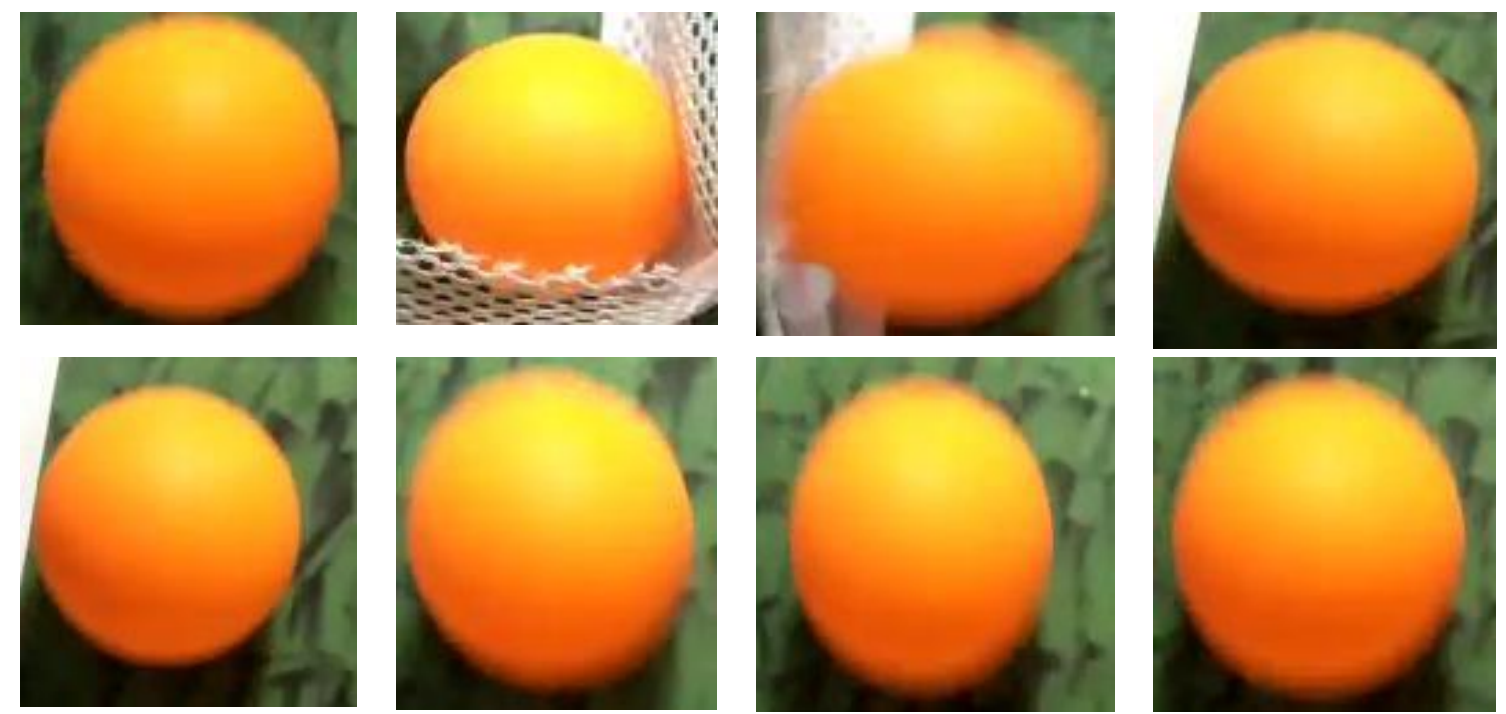

Şekil 8. Görüntü verisetinden farklı açılardan elde edilmiş top görüntüleri

\subsection{Veri İşleme ve Topun Belirlenmesi(Data Processing and Detection Ball)}

Elde edilen fotoğraflar ile oluşturulan veri kümesi üzerinden yapılacak Haar Cascade eğitimlerinden daha iyi sonuçlar almak adına veri kümesinde bulunan fotoğraflar bir takım ön işlemlere tabi tutulmuştur. $\mathrm{Bu}$ işlemleri bütün fotoğrafa uygulamak yerine, fotoğraftaki top kısmı belirlenip merkezlenerek kare şeklinde kırpılmıştır. Daha sonra ise " $140 * 140 "$ ve " $155 \times 130 "$ piksel aralığında olacak şekilde tekrar boyutlandırılmıştır. Tüm bu işlemler Python ortamında gerçekleştirilirken, top belirleme için ise ViolaJones algoritması kullanılmıştır. Viola-Jones algoritması yüksek performansı ile en çok kullanılan nesne belirleme yöntemi olarak kullanılmaktadır. 
Şekil 9'da görüldüğü gibi topu belirlemek için dikdörtgen özellikleri kullanmaktadır. Bu sayede topun oldukça hızlı belirlenmesi sağlanmaktadır. Ayrıca daha sonra oluşturulan ağın performansını yükseltmek adına veri çoğaltma yapılarak, veri kümesinde bulunan fotoğraflar, görüntü işleme teknikleri ile daha düşük ve daha yüksek parlaklık ve kontrast değerleri altında düzenlenip tekrar kaydedilerek, eğitim verisi arttırılmıştır.

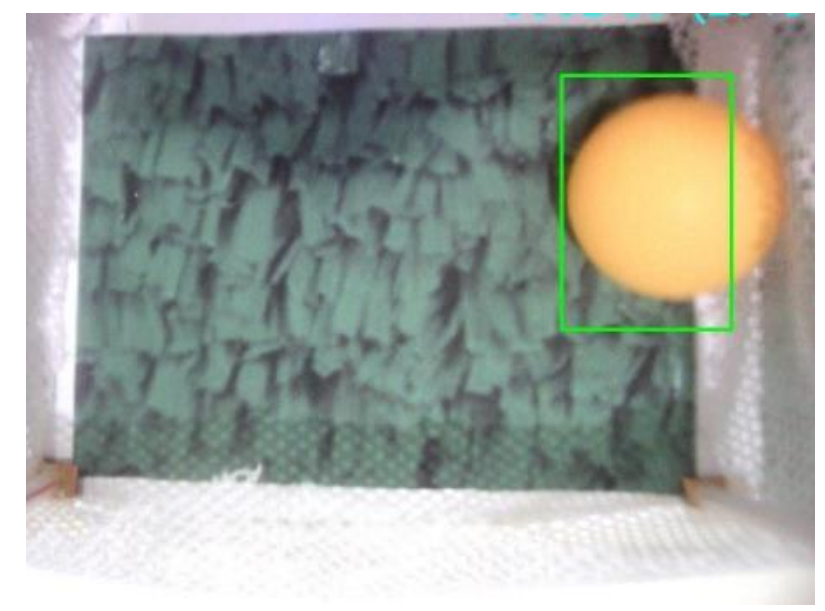

Şekil 9. Veri işlendikten sonra topun belirlenmesi

\section{4. ÖNERILEN SISTEM: GolKaSis (PROPOSED SYSTEM: GolKaSis)}

Çalışmada önerilen GolKaSis için Şekil 10'da görüldügü gibi bir futbol sahası prototipi oluşturulmuştur. Tasarlanan prototipte gol olayının tespit edilebilmesi amacıyla ceza sahası bölgesi gerçek bir futbol sahasının ölçüleri dikkate alınarak ölçeklendirilmiştir. Sistemde kameralar yardımıyla topların görüntüleri çerçeveler haline alınarak bilgisayarlı görü sistemine aktarılmaktadır. Gerçekleştirilen sistemde yapılan denemeler sonucunda, kameranın yerden yüksekliğinin en uygun video çekimlerinin elde edilebilmesi için $24 \mathrm{~cm}$ olması gerektiği belirlenmiştir. Sistemde verisetinin oluşturulması için veri tabanına topun tüm açılarını gösteren görüntüler kaydedilmektedir.
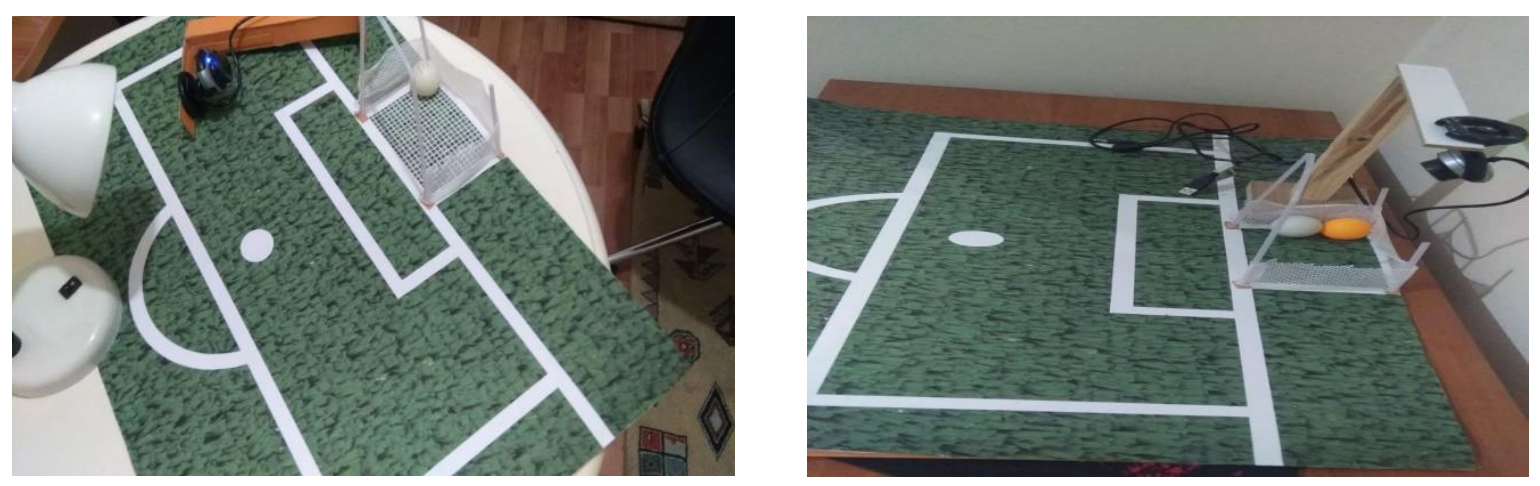

Şekil 10. Tasarlanan bilgisayarl görü destekli saha prototipi

Geliştirilen sistemin Haar Kaskad sınıflandırıcı için eğitim ve test aşamalarında kullanılan gol olayını gösteren pozitif görüntü örnekleri ve gol olmayan negatif örneklere ait olan görüntüler Şekil 11(a) ve (b)'de gösterilmiştir. Ayrıca görüntülerin bazılarının hareket halinde elde edilerek bulanık olması sağlanarak sistemin daha tutarlı çalışması sağlanmıştır. 

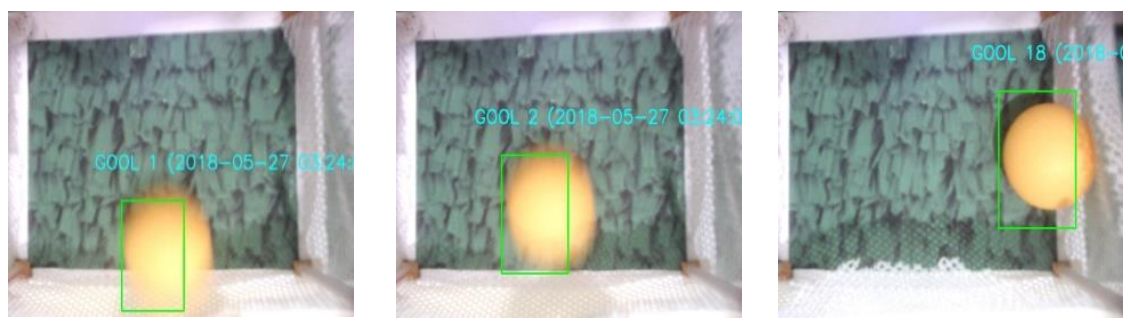

(a) Gol olayını gösteren pozitif görüntü örnekleri
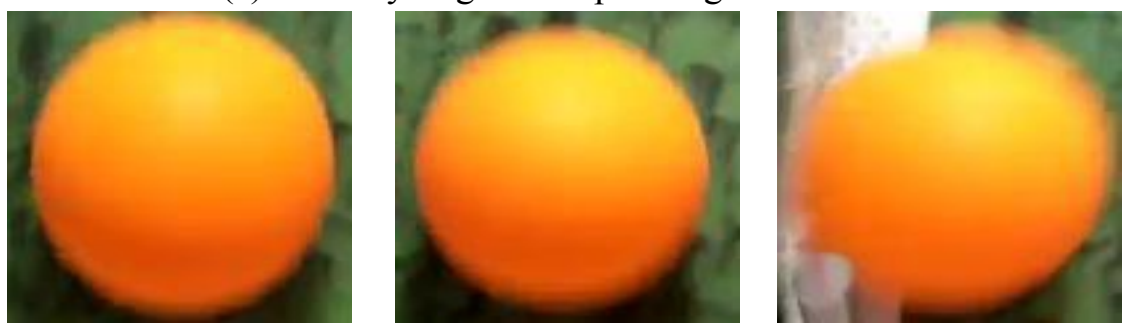

(b) Gol olmayan pozisyonları gösteren negatif görüntü örnekleri

Şekil 11. Futbol topuna ait pozitif ve negatif görüntü örnekleri (a) pozitif, (b) negatif

Sistemin çalışmasını gösteren akış şeması Şekil 12'de sunulmuştur. Bu akış şemasından da görüleceği üzere, öncelikle video çerçevesi içerisinde topun olup olmadığı belirlenmektedir. İlgili çerçevede top olduğu tespit edildikten sonra, topun kale çizgisi ile olan konumu sorgulanmaktadır. Kale çizgisini geçip geçmediği Haar sınıflandırıcı ile daha önce oluşturulan eğitim kümesi karşılaştırılarak gol olayının gerçekleşip, gerçekleşmediği GolMu fonksiyonunun içeriğindeki yapıların işletilmesi ile kestirilmektedir.

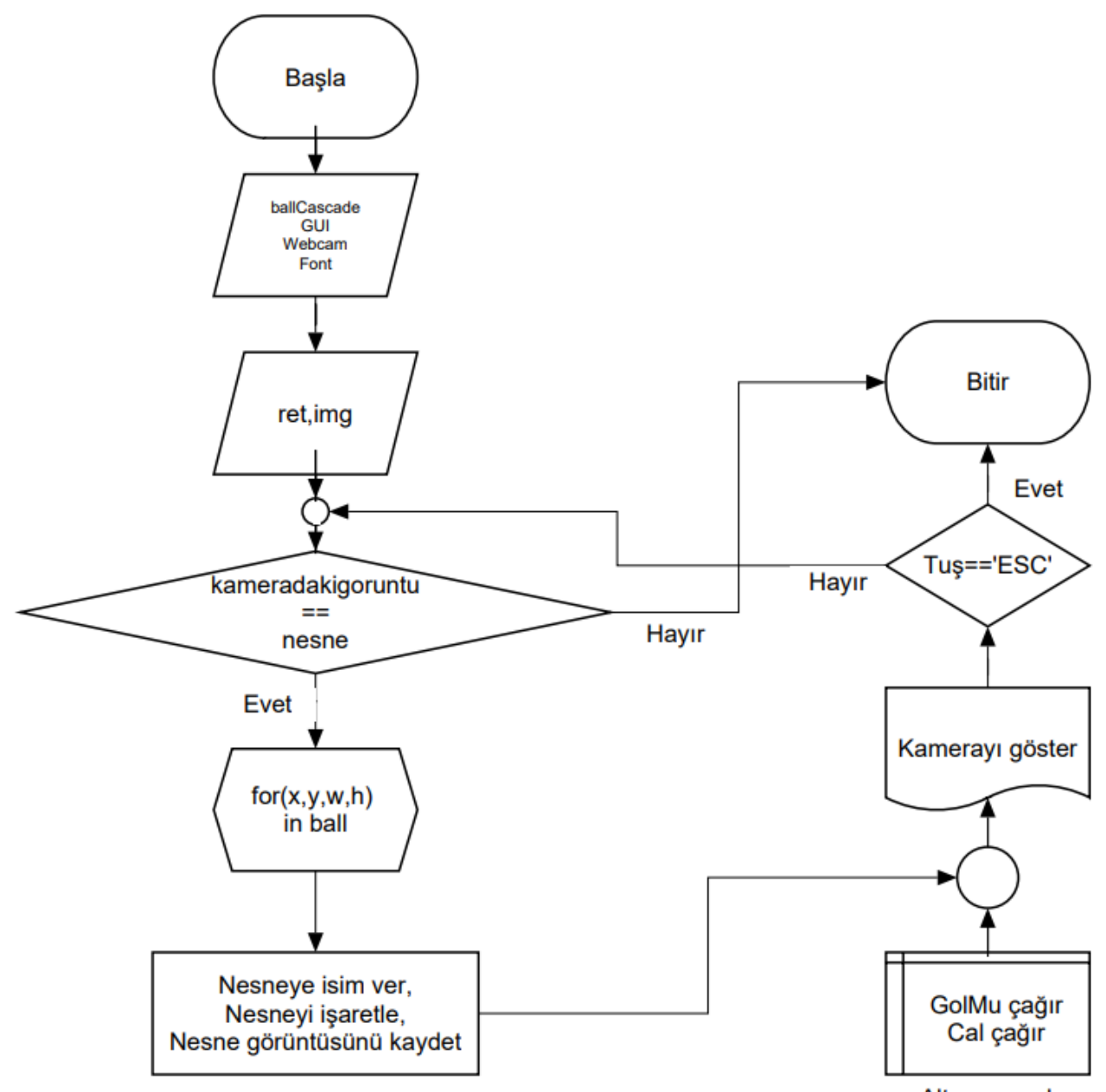

Şekil 12. Tasarlanan sistemin çalışmasını gösteren akış diyagramı 
Çalışmada veriseti oluşturulduktan sonra uygun bir konuma yerleştirilen kamera aracılığıyla alınan videonun çerçeve görüntüleri alınarak veri tabanında benzer görüntünün var olup olmadığ kontrol edilmektedir. İlk olarak alınan görüntüden topun bölgesi belirlenerek topun çevresi eşitlenir. Bu aşamadan sonra, Haar Kaskad işlemleri ile kontrol işlemleri gerçekleştirilir. Topun kameranın görüş açısında olduğu sürece nesnenin kayıt işlemleri gerçekleştirilir. Nesneye isim ataması yapılır ve nesnenin görüntüsü veri tabanına kaydedilir. Son aşamada ise kullanıcının görebileceği şekilde verilere raporlanarak kayıt altına alınır. Eğer sistemde bir eşleşme sağlanırsa, nesneye isim verilip, işaretlenip ve kaydedilir. Şekil 13'de görülebileceği gibi top anlık olarak kamera açısına girdiğinde XML dosyasındaki eğitim verisiyle eşleştiğinde top işaretlenmesi sağlanır ve gol olayı belirlenir. XML dosyasının içerisinde topun belirlenmesi ile gol olan ve olmayan pozisyonlara ait çerçevelerin bilgileri tutulmaktadır.

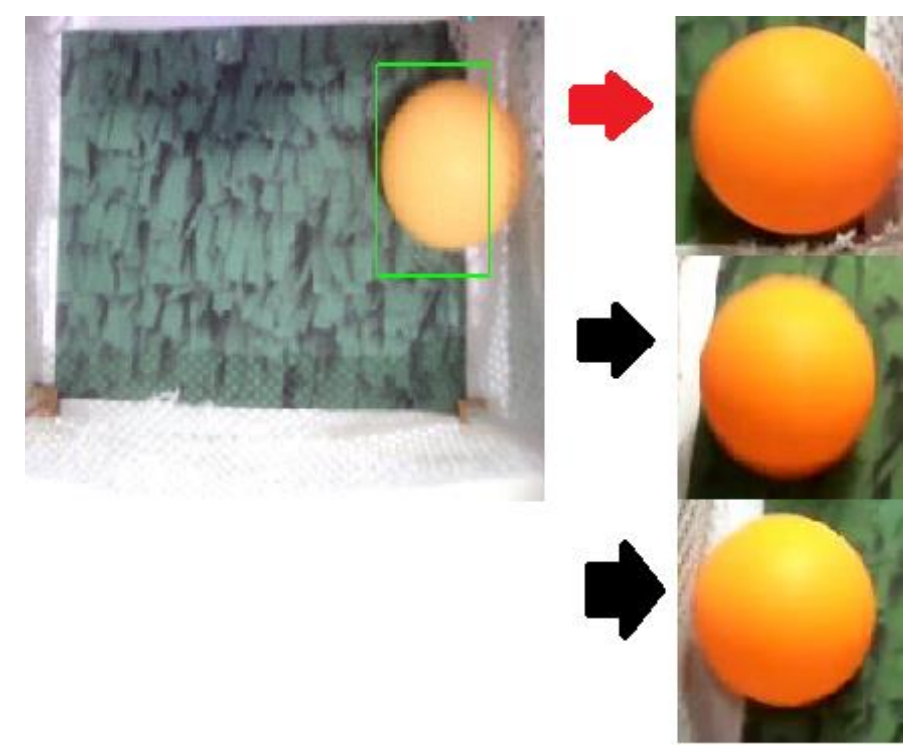

Şekil 13. Pozitif klasöründeki verilerle karşılaştırma(XML dosyasıyla karşılaş̧ırma)

Şekil 14'te ise GolKaSis ile bazı gol olaylarına yönelik örnek görüntü kolajı gösterilmiştir. Kamerada top görünmeye başladığı andan itibaren top belirlenmekte ve bilgisayarlı görü tarafından top çizgiyi tamamen geçtiği anda gol olayının tespiti gerçekleştirilmektedir. Sistem üzerinde gerçek zamanlı yapılan test işlemlerinde sistemin başarılı bir şekilde gol olayını tespit ettiği görülmüştür.

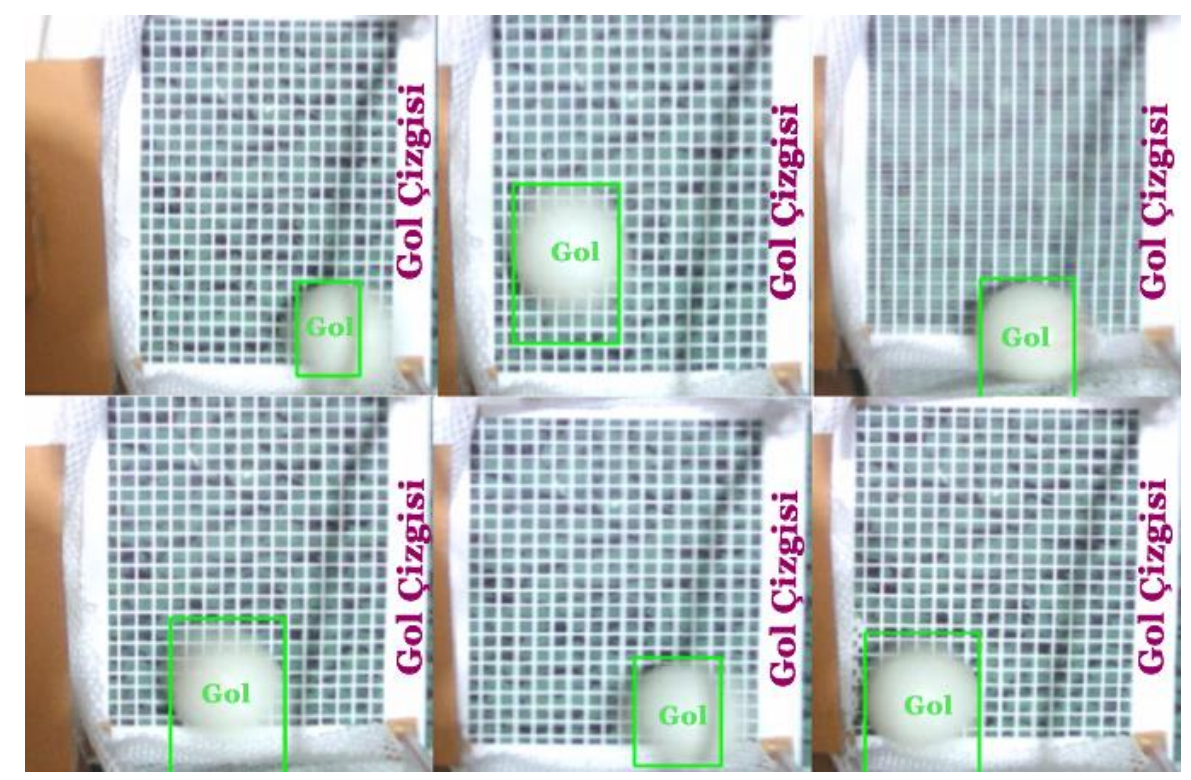

Şekil 14. Kamera tarafindan alınan görüntülerin kolajı 
Çalışma kapsamında yürütülen deneysel çalışmalarda, 2600 pozitif(gol) ve 1000 negatif (gol değil) olmak üzere toplamda 3600 video çerçevesinin \%70'i eğitim aşamasında, \%30'u ise test aşamasında kullanılmıştır. Böylece test kümesi için 780 pozitif, 300 negatif örüntü olmak üzere toplamda 1080 örnek oluşturulmuştur. Yapılan test işlemi sonucunda elde edilen sonuçları gösteren karmaşıklık matrisi Tablo 1'de sunulmuştur. Bu çizelgeden de görüleceği üzere, toplam 1080 örnek üzerinde 983 adet örnek doğru sınıflandırılarak \%91 sınıflandırma başarımı elde edilmiştir.

Tablo 1. Test veri kümesine ait karmaşıklık matrisi sonuçları

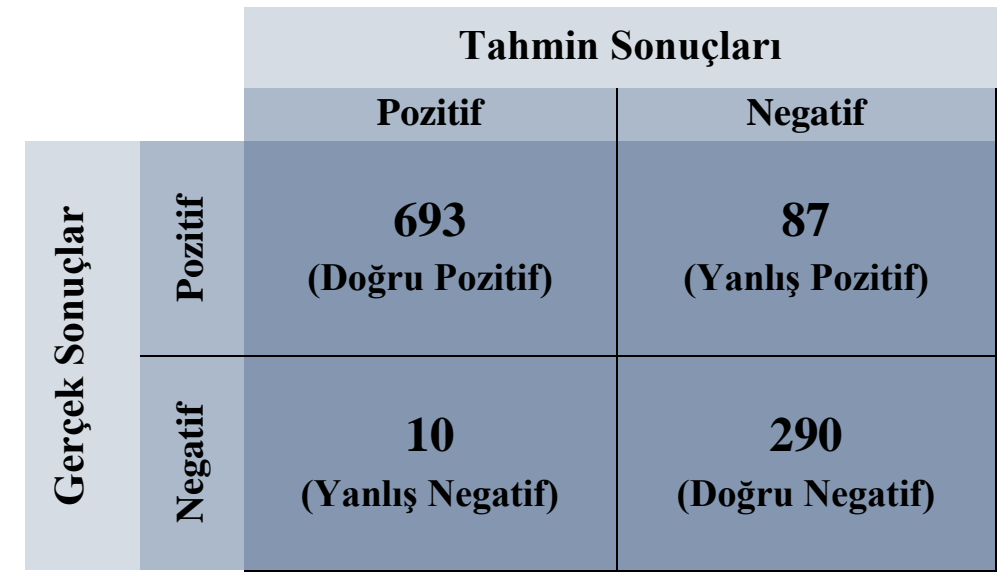

\section{SONUÇLAR (CONCLUSIONS)}

Bu çalışmada, gelişen teknoloji ile birlikte futbol sahalarında topun çizgiyi geçip geçmediği ile ilgili temel bir bilgisayarlı görü sistemi(GolKaSis) tasarlanmıştır. Sistemde öncelikle, tasarlanan futbol sahası prototipinde uygun bir bölgeye yerleştirilen kameradan elde edilen videolardan alınan görüntüler negatif ve pozitif olarak ayrılmıştır. Bu görüntülerden pozitif olanlar gol olayını gösterenlerden, negatif olanlar ise gol olayının meydana gelmediği video görüntülerinden oluşmaktadır. Geliştirilen bilgisayarlı görü sisteminde gerçek zamanlı alınan video görüntüleri ile pozitif görüntülerin eşleştirilmesi ise Haar Kaskad Sınıflandırıcı sağlanarak gol olayı tespit edilmektedir. Tasarlanan prototip üzerinde yapılan test işlemlerinde önerilen bilgisayarlı görü sisteminin gol olayını $\% 91$ başarım oranı ile doğru olarak tespit ettiği görülmüştür. Ayrıca çalışmada, videolardan elde edilen görüntülerdeki ışık şiddetinin gol olayının doğru olarak tespit edilmesine etkisi olduğu görülmüştür. Bu nedenle kullanılan kameranın özellikleri de göz önüne alınarak 1şık şiddetinin uygun şekilde ayarlanması gerekmektedir.

Çalışmanın bundan sonraki aşamalarında daha gerçek bir futbol sahası üzerinde alınan videolardan gol olayının tespit edilmesi amaçlanmaktadır. Ayrıca derin öğrenme yöntemleri gibi farklı algoritmalar ile de sistemin karşılaştırmalarının yapılması planlanmaktadır.

\section{KAYNAKLAR (REFERENCES)}

[1] Psiuk R., Seidl T., Strauß W., Bernhard J. Analysis of goal line technology from the perspective of an electromagnetic field based approach. Procedia Engineering, 72(279-284), (2014).

[2] Peker M., Özkaraca O. Büyük ölçekli veri setleri için GPU hızlandırmalı melez bir GA-SVM: Cu-GASVM. Gazi Üniversitesi Fen Bilimleri Dergisi Part C: Tasarım ve Teknoloji, 6:3(581-591), (2018).

[3] Reid I., Zisserman A. Goal-directed video metrology. 4th European Conference on Computer Vision '96, Cambridge, (April 1996).

[4] Ancona N., Cicirelli G., Branca A., Distante A. Goal detection in football by using support vector machines for classification. International Joint Conference on Neural Networks (IJCNN'01), 1(611616), (2001). 
[5] Chen S. C., Shyu M. L., Zhang C., Luo L., Chen M. Detection of soccer goal shots using joint multimedia features and classification rules. $M D M / K D D^{\prime} 03$, Washington, DC, USA, (2003).

[6] Wan K., Yan X., Yu X., Xu C. Real-time goal-mouth detection in MPEG soccer video. Proceedings of the eleventh ACM international conference on Multimedia, (pp. 311-314), (2003).

[7] D’Orazio T., Leo M., Spagnolo P., Nitti M., Mosca N., Distante A. A visual system for real time detection of goal events during soccer matches. Computer Vision and Image Understanding, 113:5(622-632), (2009).

[8] Yang Y., Lin S., Zhang Y., Tang S. Highlights extraction in soccer videos based on goal-mouth detection. 9th International Symposium on Signal Processing and Its Applications (ISSPA 2007), (pp. 1-4), (2007, February).

[9] Shi P., Yu X. Q. Goal event detection in soccer videos using multi-clues detection rules. International Conference on Management and Service Science (MASS'09), (pp. 1-4), (2009, September).

[10] Khatoonabadi S. H., Rahmati M. Automatic soccer players tracking in goal scenes by camera motion elimination. Image and Vision Computing, 27:4(469-479), (2009).

[11] Gao X., Niu Z., Tao D., Li X. Non-goal scene analysis for soccer video. Neurocomputing, 74:4 (540548),. (2011).

[12] Spagnolo P., Leo M., Mazzeo P., Nitti M., Stella E., Distante A. Non-invasive soccer goal line technology: A real case study. Proceedings of the IEEE Conference on Computer Vision and Pattern Recognition Workshops (pp. 1011-1018), (2013).

[13] Ryall E. Are there any Good Arguments Against Goal-Line Technology?. Sport, Ethics and Philosophy, 6:4(439-450), (2012).

[14] ScienceABC, https://www.scienceabc.com/innovation/how-does-the-goal-line-technologywork.html, Erişim Tarihi: 04/12/2018.

[15] FIFA Goal-line Technology, Recommendations for implementation in competitions based on experience from the FIFA Club World Cup Japan 2012, https://www.fifa.com/mm/document/fifaqualityprogramme/goallinetechnology/02/01/77/01/gltwebe n.pdf, Erişim Tarihi: 02/12/2018.

[16] physics.org, http://www.physics.org/article-questions.asp?id=125, Erişim Tarihi: 02/12/2018.

[17] Sky Sports https://www.skysports.com/football/news/11095/11395534/var-at-the-world-cup-whencan-video-assistant-referees-be-used-will-fans-be-informed-of-decisions, Erişim Tarihi: 02/12/2018

[18] Eldem A., Eldem H., Palalı A. Görüntü İşleme Teknikleriyle Yüz Algılama Sistemi Geliştirme. Bitlis Eren Üniversitesi Fen Bilimleri Dergisi, 6:2(44-48), (2017).

[19] Viola P., Jones M. J. Robust real-time face detection. International Journal of Computer Vision, 57:2(137-154), (2004).

[20] Wilson P. I., Fernandez J. Facial feature detection using Haar classifiers. Journal of Computing Sciences in Colleges, 21:4(127-133), (2006).

[21] Cascade Trainer GUI, http://amin-ahmadi.com/cascade-trainer-gui/ Erişim Tarihi: 02/12/2018.

[22] Viola P., Jones M. Rapid object detection using a boosted cascade of simple features. In Computer Vision and Pattern Recognition, 2001 (CVPR 2001). Proceedings of the 2001 IEEE Computer Society Conference on (Vol. 1, pp. I-I), (2001). 